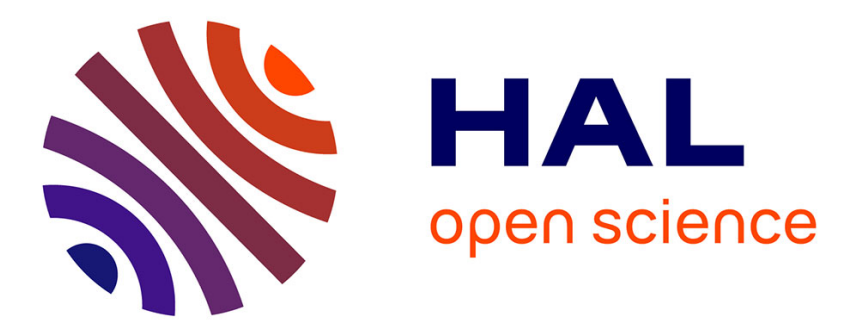

\title{
Plasma in spark plasma sintering of ceramic particle compacts
}

Rachel Marder, Claude Estournès, Geoffroy Chevallier, Rachman Chaim

\section{To cite this version:}

Rachel Marder, Claude Estournès, Geoffroy Chevallier, Rachman Chaim. Plasma in spark plasma sintering of ceramic particle compacts. Scripta Materialia, 2014, vol. 82, pp. 57-60. 10.1016/j.scriptamat.2014.03.023 . hal-01130774

\section{HAL Id: hal-01130774 https://hal.science/hal-01130774}

Submitted on 12 Mar 2015

HAL is a multi-disciplinary open access archive for the deposit and dissemination of scientific research documents, whether they are published or not. The documents may come from teaching and research institutions in France or abroad, or from public or private research centers.
L'archive ouverte pluridisciplinaire HAL, est destinée au dépôt et à la diffusion de documents scientifiques de niveau recherche, publiés ou non, émanant des établissements d'enseignement et de recherche français ou étrangers, des laboratoires publics ou privés. 


\section{OATAO \\ Open Archive Toulouse Archive Ouverte}

\section{Open Archive TOULOUSE Archive Ouverte (OATAO)}

OATAO is an open access repository that collects the work of Toulouse researchers and makes it freely available over the web where possible.

This is an author-deposited version published in : http://oatao.univ-toulouse.fr/ Eprints ID : 13635

To link to this article : DOI:10.1016/j.scriptamat.2014.03.023

URL : http://dx.doi.org/10.1016/j.scriptamat.2014.03.023

\section{To cite this version :}

Marder, Rachel and Estournès, Claude and Chevallier, Geoffroy and Chaim, Rachman Plasma in spark plasma sintering of ceramic particle compacts. (2014) Scripta Materialia, vol. 82. pp. 57-60. ISSN 1359-6462

Any correspondance concerning this service should be sent to the repository administrator: staff-oatao@listes-diff.inp-toulouse.fr 


\title{
Plasma in spark plasma sintering of ceramic particle compacts
}

\author{
R. Marder, ${ }^{\mathrm{a}}$ C. Estournès, ${ }^{\mathrm{b}, \mathrm{c}}$ G. Chevallier ${ }^{\mathrm{b}, \mathrm{c}}$ and R. Chaim ${ }^{\mathrm{a}, *}$ \\ ${ }^{a}$ Department of Materials Science and Engineering, Technion - Israel Institute of Technology, \\ Haifa 32000, Israel \\ ${ }^{\mathrm{b}}$ Université de Toulouse, UPS, INP, Institut Carnot Cirimat, 118, route de Narbonne, \\ F-31062 Toulouse Cedex 9, France \\ ${ }^{\mathrm{c}}$ CNRS, Institut Carnot Cirimat, F-31062 Toulouse, France
}

\begin{abstract}
Cuboidal LiF microcrystal powder was densified by spark plasma sintering at different pressures up to $500{ }^{\circ} \mathrm{C}$. Densification at pressures above the yield stress occurred by plastic deformation and strain hardening. Densification at $2 \mathrm{MPa}$, below the yield stress, occurred by particle rearrangement assisted by viscous flow at the particle surfaces. Scanning electron microscopy examination of the fracture surfaces of the partially dense specimens revealed partial melting of the particle surfaces due to the plasma. The onset temperature for plasma formation was $180^{\circ} \mathrm{C}$.
\end{abstract}

Keywords: Spark plasma sintering; Powder consolidation; Ceramics; Densification; Plasma

Spark plasma sintering (SPS) and other electric field activated sintering techniques have been investigated at great length and are used for rapid fabrication of nanocrystalline ceramics. Although these techniques result in highly enhanced densification kinetics, the exact details of the densification mechanisms are still the subject of investigation and modelling. Recently, different models for rapid field-affected sintering, densification and grain growth of ceramic oxide nanoparticles were proposed. These refer either to the formation of a high density of defects at the surfaces and grain boundaries [1-3] and a decrease in the grain boundary energy [4], or to enhanced diffusion through an amorphous layer at the particle surfaces due to surface discharges and possible plasma formation [5-9]. Experimental evidence has been provided for the breakdown of the nonconducting oxide layers at the surfaces of metallic nanoparticles subjected to low voltages, simulating the SPS conditions [9-12]. In ceramic systems such as $\mathrm{Al}_{2} \mathrm{O}_{3}$ [13], YAG [5] and Y-TZP [14,15], evidence for crystal growth has been observed within the pore cavities and at the pore surfaces, together with surface

\footnotetext{
* Corresponding author. Tel.: +972 4 8294589; fax: $+972 \quad 4$

8295677; e-mail: rchaim@technion.ac.il
}

protrusions. Part of these growth processes are probably related to the evaporation-condensation mechanism, which most likely involves the formation of a liquid phase or layer at the nanoparticle free surfaces. This aspect of enhanced densification kinetics, due to surface softening, was discussed with respect to the elastic nature of the oxide nanoparticle at the threshold for electric current percolation and possible plasma formation $[6,16]$.

In our recent study on densification by SPS of LiF as a model system for ductile ceramics, the densification behavior was described very well by plastic deformation via the hot isostatic pressing model [17]. The plastic deformation model considered the changes in the yield stress and stress concentration factor arising from the particle and pore shapes, as well as the strain hardening behavior of $\mathrm{LiF}$ with temperature. However, densification also took place at pressures below the yield stress at the corresponding SPS temperature. Here we show scanning electron microscopy (SEM) images which directly confirm the local melting of the LiF microcrystals at low pressures, presumably due to the spark and plasma formed. We further analyze the densification via the liquid phase using simple criteria for spark and plasma formation in SPS [6]. 
High-purity LiF (99.995\%, Sigma-Aldrich) cuboidal microcrystals with an average edge size of $6.5 \pm 2.6 \mu \mathrm{m}$ were used. A heating rate of $100{ }^{\circ} \mathrm{C} \mathrm{min}^{-1}$ was applied using the Dr. Sinter 2080 apparatus with a 12-2 DC-pulsed sequence. Detailed descriptions of the experimental conditions and the shrinkage analysis are given elsewhere [17]. Uniaxial pressures of 2, 32 and $64 \mathrm{MPa}$ were applied at the start of the SPS, and were held constant throughout the heating, which was up to $500^{\circ} \mathrm{C}$. This was followed by simultaneous release of pressure and curtailment of current. The relative density of the $\mathrm{LiF}$ microcrystal powder compacts at three different pressures with heating up to $500{ }^{\circ} \mathrm{C}$ is shown by the solid curves in Figure 1. Densification occurs at all pressures, albeit to different extents. At first glance, this can be attributed to the plastic deformation of the LiF microcrystals due to their soft nature. Using the hot isostatic pressing (HIP) plastic deformation model [18], and considering various aspects of the material and the process parameters, and their change with temperature (particle and pore shape, stress intensity factor, strain hardening behavior, etc.), the density at different SPS pressures was calculated and is shown as dotted curves in Figure 1 (detailed analysis is given elsewhere [17]). Good agreement between the experimental and theoretical curves was found at the higher pressures. The temperature dependence of the yield stress of LiF single crystals, averaged over different slip systems according to their abundance [17], is shown in Figure 2. The electrical conductivity of the dielectric granular compact subjected to potential gradient (voltage) dictates the onset temperature for the current percolation threshold, which is within the range $10^{-9}-10^{-5} \mathrm{~S} \mathrm{~cm}^{-1}$ [6]. The temperature dependence of the electrical conductivity $[19,20]$ of $\mathrm{LiF}$ is also shown in Figure 2. The yield stress and electrical conductivity dependencies on the temperature determine two temperature windows (Fig. 2) in which the densification during SPS is enhanced by plastic deformation and/ or plasma formation [6]. It is apparent from Figure 2a that, under an applied SPS pressure of $100 \mathrm{MPa}$, the plastic deformation window starts at room temperature and precedes the plasma formation window. Consequently, plastic deformation will form a continuous particle

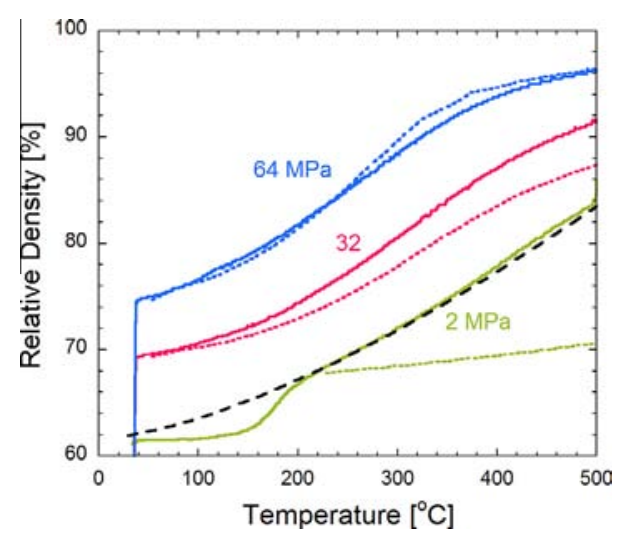

Figure 1. Experimental (solid) and calculated (dotted) shrinkage curves, using the HIP plastic deformation model. The densification calculated via viscous sintering at $2 \mathrm{MPa}$ is shown by the dashed (black) curve.
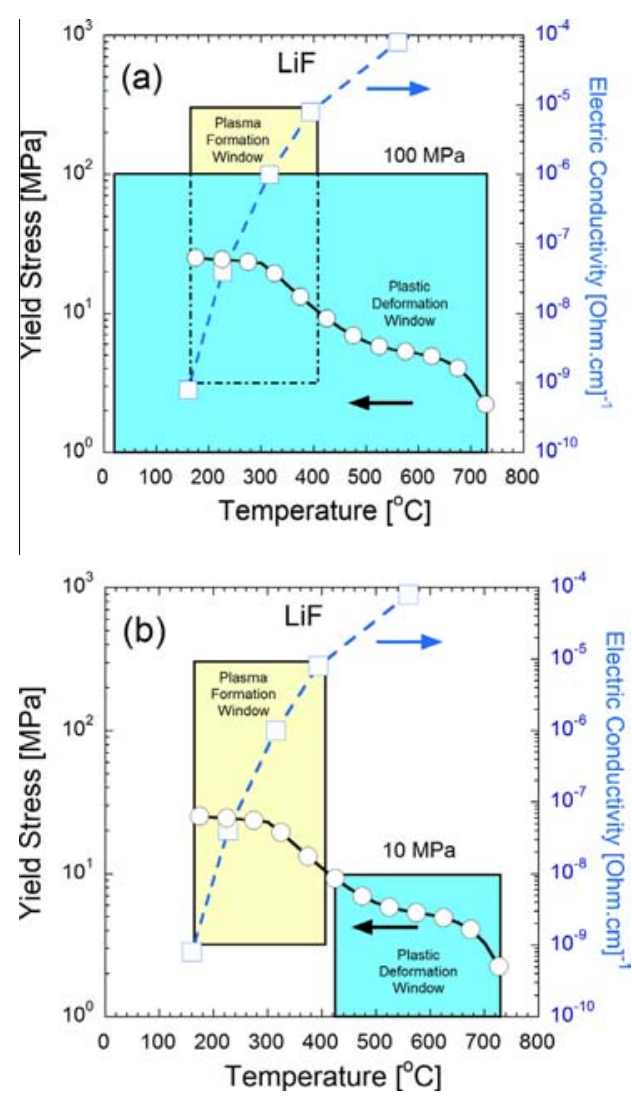

Figure 2. Diagrams showing the temperature windows determined for plastic deformation and plasma formation for granular $\mathrm{LiF}$ compacts at (a) $100 \mathrm{MPa}$ and (b) $10 \mathrm{MPa}$ applied pressure. The window at the lower temperature determines the active densification process as it starts.

network, which, in turn, may nullify any possible particle charging and discharging over the gaps within the unsintered powder compact. Nevertheless, decreasing the applied stress to $2 \mathrm{MPa}$ (which is below the yield stress up to $\sim 730^{\circ} \mathrm{C}$ ) provides the conditions required for plasma formation prior to plastic deformation (Fig. 2b). However, when plasma is formed, the local temperature may increase significantly, hence the plastic deformation window will become active at lower temperatures. Following the SPS pressure of $2 \mathrm{MPa}$ in Figure 2b, significant effects of plasma are expected and should be observable due to the lack of plastic deformation.

SEM images from the fractured surfaces of the specimen sintered at $2 \mathrm{MPa}$ revealed local melting at the particle edges and corners of the larger particles (Fig. 3a), as well as on their surfaces (Fig. 3b). Many particle surfaces contain traces of liquid layers that were solidified while flowing. Additionally, material jets formed from liquid are visible between particles (Fig. 3c). This indicates that very high local temperatures, above $845^{\circ} \mathrm{C}$ (melting point of $\mathrm{LiF}$ ), must be present during the process, the final temperature of which was only $500{ }^{\circ} \mathrm{C}$. The melted corners, edges and surfaces may be clearly distinguished from the cleaved fracture surfaces. The melted corners of the cubes most often face towards the internal cavity rather than to the fractured surface, which made their identification and selection easier. The strong local melting is characteristic of the spark formed between the partially 

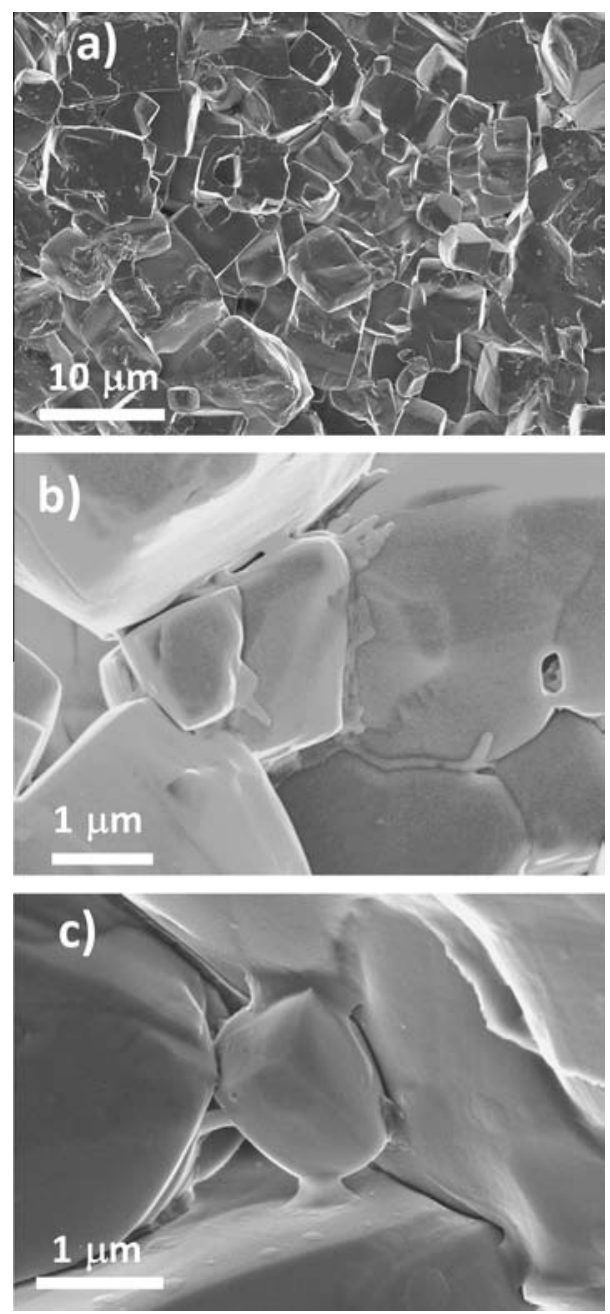

Figure 3. SEM images of LiF heated by SPS to $500^{\circ} \mathrm{C}$ at $2 \mathrm{MPa}$. (a) Melting of the particle corners, (b) surfaces wetted by a flowing liquid and (c) the material jet formed by the spark impact are visible.

melted corner (previously unmelted) and the corner/edge/ surface of the opposite particle over the gap. Thorough SEM examination of the particle surfaces at different magnifications revealed that the finer particles apparently melted and wetted the larger particle surfaces at the cavities. Joule heating could explain the temperature increase in the vicinity of the contact points; however, it cannot explain the large extent of the liquid and melted surfaces, especially the material jets observed in the specimens. Plasma formation is highly exothermic, and the temperature may rise even to several thousand degrees Celsius. The low conductivity of $\mathrm{LiF}$ at lower temperatures allows the passage of limited electric current through the powder compact, as long as the particles touch each other. However, a gap in the microstructure will obstruct the current, and cause charge to build up on the particle surfaces beside the gap. Surface discharges will occur when enough charge has accumulated at the surfaces. This can be by a spark that generates plasma when the threshold for the current percolation is reached. Due to the fractal nature of the spark, certain locations with high electron/ion flux are prone to melting (Fig. 3c). Plasma often has a self-propagating nature when ignited.
Consequently, the locally high temperature induced by the plasma can cause the melting and evaporation of smaller particles, and would explain why only a few small particles were observed in the partially sintered microstructure; no sufficient time is available during the SPS for equilibrium grain growth. Discharges and melting due to the plasma were observed mainly at the large particles; these can most probably accumulate higher values of surface charge and concentrate it via their corners/ edges towards the opposite surface across the gap. This plasma formation scenario is consistent with the microstructure observed.

Limited plastic deformation occurred in the specimens sintered at $2 \mathrm{MPa}$, as can be seen in the SEM images (Fig. 3a); the particles retained their original cuboidal morphology. The densification curve at $2 \mathrm{MPa}$ (Fig. 1) exhibits a linear behavior above $200{ }^{\circ} \mathrm{C}$, in contrast to those at the higher pressures. The formation of a thin liquid layer at the particle surfaces or surface softening, due to the plasma, will release the stress concentration due to the particle morphology, and also release the strain hardening at the particle surfaces. This is in accordance with sintering by viscous flow at the particle surfaces, where the particle core is rigid [21]. This aspect was evaluated by the two following approaches.

First, the onset temperature for viscous plastic deformation is set by the strain point, via the engineering approach for the glass deformation behavior [22]. The strain point corresponds to the viscosity value of $3 \times 10^{13} \mathrm{Pas}$, and represents the onset temperature below which fracture will occur prior to plastic deformation in glass. The Stocks-Einstein equation relates between the melt viscosity, $\eta$, and the corresponding volume diffusion coefficient, $D_{\mathrm{V}}$, of the diffusing specie with ionic radius $r$ within it:

$\eta=\frac{k T}{3 \pi r D_{\mathrm{V}}}$

where $k$ and $T$ are the Boltzmann's constant and temperature, respectively. Using the diffusion coefficient of fluorine [23], as the slowest ionic specie, with ionic radius of $0.119 \mathrm{~nm}$, the corresponding temperature for the strain point viscosity is calculated as $\sim 180^{\circ} \mathrm{C}$. This temperature is in excellent agreement with the temperature range 160-200 ${ }^{\circ} \mathrm{C}$, where shrinkage starts at $2 \mathrm{MPa}$ (Fig. 1) and may confirm the viscous flow at the particle surfaces.

Second, using the previous HIP model for densification at the higher pressures [17], without stress concentration or strain hardening, the new calculated curve is shown as a dashed line in Figure 1. Very good agreement was found between the calculated and experimental densification curves when the shrinkage rate is stabilized, confirming again the effect of the liquid layer at the particle surfaces in enhancing the densification kinetics.

Finally, the fact that these liquid layers were uncovered until now in many investigations apparently arises from the SPS conditions, the ceramic composition, particle size and morphology. Ceramics with higher melting points are harder to melt, as was found in the YAG system [5]. As the particle size decreases, more surfaces per 
unit volume exist in the compact. For a given SPS condition (i.e. current density, voltage, pulse/pause duration) the local accumulated charge decreases with decreasing particle size, thus reducing the probability of a discharge occurring. Sharper particle morphologies should provide loci at the surface with a greater probability of discharge. Plasma will form during the SPS provided the plasma temperature window precedes the yield temperature window [6]. Consequently, in order to take advantage of the plasma heating, the SPS load should be applied only after the temperature for onset of plasma formation is reached.

In summary, spark and plasma were formed during the SPS of LiF at $2 \mathrm{MPa}$ pressure below the yield stress. The onset temperature was analyzed to be $\sim 180^{\circ} \mathrm{C}$, in excellent agreement with the shrinkage data. Direct observation by SEM revealed traces of local melting within the cavities, and material jets between particles. The present results show that the enhancement of the densification kinetics during the SPS of non-conducting ceramics is associated with the existence of plasma.

SPS experiments were performed at the Plateforme Nationale CNRS de Frittage Flash (PNF2-CNRS) located at University Toulouse III Paul Sabatier. R.M. acknowledges support provided by the Israel Ministry of Science and Technology through the Women-in-Science fellowship.

[1] H. Yoshida, Y. Sakka, T. Yamamoto, J.M. Lebrun, R. Raj, J. Eur. Ceram. Soc. 34 (2014) 991.

[2] M. Cologna, J.S.C. Francis, R. Raj, J. Eur. Ceram. Soc. 31 (2011) 2827.

[3] J. Narayan, Scripta Mater. 68 (2013) 785.

[4] J. Wang, D. Yang, H. Conrad, Scripta Mater. 69 (2013) 351.
[5] R. Chaim, R. Marder-Jeackel, J.Z. Shen, Mater. Sci. Eng., A 429 (2006) 74.

[6] R. Chaim, J. Mater. Sci. 48 (2013) 502.

[7] J. Narayan, Scripta Mater. 69 (2013) 107.

[8] Y.J. Wu, J. Li, X.M. Chen, K. Kakegawa, Mater. Sci. Eng., A 527 (2010) 5157.

[9] D. Demirskyi, H. Borodianska, S. Grasso, Y. Sakka, O. Vasylkiv, Scripta Mater. 65 (2011) 683.

[10] C.S. Bonifacio, T.B. Holland, K. van Benthem, Acta Mater. 48 (2014) 140.

[11] G.S. Park, X.S. Li, D.C. Kim, R.J. Jung, M.J. Lee, S. Seo, Appl. Phys. Lett. 91 (2007) 222103.

[12] T.B. Holland, A.M. Thorn, C.S. Bonifacio, A.K. Mukherjee, K. van Benthem, Appl. Phys. Lett. 96 (2010) 243106.

[13] K. Kumeda, Y. Nakamura, A. Takata, K. Ishizaki, J. Ceram. Soc. Jpn. 107 (1999) 187.

[14] M.C. Steil, D. Marinha, Y. Aman, J.R.C. Gomes, M. Kleitz, J. Eur. Ceram. Soc. 33 (2013) 2093.

[15] A. Cordier, M. Kleitz, M.C. Steil, J. Eur. Ceram. Soc. 32 (2012) 1473.

[16] R. Chaim, R. Marder, C. Estournès, Z. Shen, Adv. Appl. Ceram. 111 (2013) 280.

[17] R. Marder, C. Estournès, G. Chevallier, S. Kalabukhov, R. Chaim, J. Mater. Sci. (2014), http://dx.doi.org/ 10.1007/s10853-013-7786-7.

[18] A.S. Helle, K.E. Easterling, M.F. Ashby, Acta Metall. 33 (1985) 2163.

[19] M. Dubois, P. Bergé, G. Blanc, Discuss. Faraday Soc. 31 (1961) 167.

[20] V. Trnovcová, P.P. Fedorov, Č. Bárta, V. Labaš, V.A. Meleshina, B.P. Sobolev, Solid State Ionics 119 (1999) 173.

[21] M.N. Rahaman, Ceramic Processing and Sintering, Marcel Dekker, New York, 2003.

[22] E.B. ShandModern Materials. Engineering Glass, vol. 6, Academic Press, New York, 1968.

[23] H. Matzke, J. Phys. Chem. Solids 32 (1971) 437. 